\title{
Fundamental study of ductile-regime diamond turning of single crystal gallium
}

\author{
arsenide

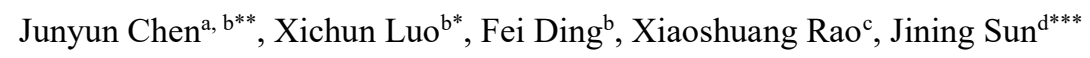 \\ ${ }^{a}$ College of Vehicles and Energy, Yanshan University, Qinhuangdao, 066004, China \\ ${ }^{\mathrm{b}}$ Centre for Precision Manufacturing, DMEM, University of Strathclyde, Glasgow G1 1XQ, UK \\ c School of Mechatronics Engineering, Harbin Institute of Technology, Harbin 150001, China \\ d School of Engineering and Physical Science, Heriot-Watt University, Edinburgh EH14 4AS, UK \\ ${ }^{*}$ Corresponding author E-mail address: *xichun.luo@strath.ac.uk; ${ }^{* *}$ sophiacjy@ysu.edu.cn; ${ }^{* *}$ iining.sun@hw.ac.uk
}

\begin{abstract}
Gallium arsenide (GaAs) components, ranging from the planar substrate to those possessing complicated shapes and microstructures, have attracted extensive interest regarding their applications in photovoltaic devices, photodetectors and emerging quantum devices. Single point diamond turning (SPDT) is regarded as an excellent candidate for an industrially viable mechanical machining process, as it can generate nano-smooth surfaces, even on some hard-to-machine brittle materials such as silicon and silicon carbide, with a single pass. However, the extremely low fracture toughness and strong anisotropic machinability of GaAs makes it difficult to obtain nano-smooth, crack-free machined surfaces. To bridge the current knowledge gaps in understanding the anisotropic machinability of GaAs, this paper studied the mechanical material properties of (001)-oriented GaAs through indentation tests, assuming the diagonals of the indenter acted in the similar way of the cutting edge of a diamond tool with a negative rake angle. The results showed that the (001) plane of the GaAs material displayed harder and more brittle when indented along direction I (one diagonal of indenter parallel to the $<110>$ orientation) compared to direction II (one diagonal of indenter parallel to the $<100>$ orientation), which coincides with anisotropic machined surface quality by SPDT. This finding reveals, for the first time, that the strong crystallographic orientation dependence of both hardness and fracture toughness represents the underlying mechanism for the anisotropic machinability of GaAs. The paper presents a novel approach to evaluate the critical depth of cut under a high cutting speed comparable to SPDT and to determine the maximum feed rate for ductile-regime diamond turning. The $26.57 \mathrm{~nm}$ critical depth of cut was obtained for the hardest cutting direction using a large negative rake angle diamond tool. Finally, a nano-smooth surface was successfully generated along all the orientations in ductile-regime diamond turning, in which the material remove mechanism is considered as plastic deformation caused by high-density dislocations and the subsurface layer without any cracks remains single crystal structure. The results proves the proposed evaluation approach
\end{abstract}


for the critical depth of cut and the maximum allowed feed rate is highly effective for guiding the ductile-regime machining of brittle materials.

Keywords: Gallium arsenide; Diamond turning; Mechanical properties; Anisotropy; Critical depth of cut.

\section{Introduction}

Gallium arsenide (GaAs) outperforms silicon in the aspects of larger band gap, better stopping power, higher resistivity, carrier mobility and radiation hardness [1-10]; therefore, it is being applied in efficient photovoltaic devices [1-3], photodetectors [4], microwave devices [5], radiation detectors [6-8], lightamplification devices [9] and other optoelectronics [10]. Furthermore, due to its high refractive index, GaAs has become a favourite candidate material for emerging quantum devices, for instance, as a solid immersion lens applied in a quantum emitter that can effectively improve the light-materials' interactions for an emitter buried in a solid-state environment [11]. Overall, GaAs components, ranging from planar substrates to those possessing complicated shapes or microstructures, have recently attracted extensive research interest. In general, lapping [12], chemical polishing [13-14] or chemical mechanical polishing [15-16] are used to obtain planar GaAs substrates; however, these manufacturing processes are extremely time-consuming. Electrochemical wet stamping and laser micromachining [17-19] have been used to fabricate microstructures on GaAs substrate. However, these methods have difficulty of meeting the required high form accuracy when compared to mechanical processing [13]. Recently, focused ion beam (FIB) machining has been used to successfully obtain GaAs quantum emitters that possess a hemispherical cavity of $1 \mu \mathrm{m}$ curvature radius to meet the required form accuracy [11]. However, FIB machining is limited in processing an area in the scale of a few or tens of microns because of its extremely low material removal rate. There is an urgent need to develop an industrially viable manufacturing technique for the mass production of GaAs-enabled devices.

Single point diamond turning (SPDT) has been regarded as an excellent mechanical machining process to generate nano-smooth machined surfaces with a single machining pass, and it can also generate three dimensional freeform surfaces and micro/nano structures even on hard and brittle materials, such as $\mathrm{Si}$ and $\mathrm{SiC}$ [20-23]. Furthermore, the components machined by diamond turning have a much better metallurgical structure than those obtained through polishing or lapping processes. Thus, diamond turning offers flexibility of the generated figure, better-step definition, deterministic form accuracy and economy of fabrication time [22]. However, GaAs is indeed an extremely challenging brittle material to machine because of its low fracture toughness and strong anisotropy in comparison with other typical brittle materials [24, 26]. Jasinevicius found 
that the ductile machining of (001)-oriented GaAs cannot be realised even with the extremely small feed rate of $1.25 \mu \mathrm{m} / \mathrm{rev}$ during SPDT, although a smooth surface can be generated under the same condition for (001)oriented silicon [25]. Fang and Yuan reported a mirror surface of GaAs was achieved in diamond turning, without providing further information on the crystallographic plane nor the orientation of the machined surface [26]. A previous study of the authors showed the strong anisotropic machinability of (001)-oriented GaAs because the machined surface exhibited four obvious fan-shaped sections, as shown in Fig. 1. Cutting along the $<110>$ direction cannot gain a complete ductile response even with the extremely small feed rate of $0.5 \mu \mathrm{m} / \mathrm{rev}$, while it is relatively easy to achieve ductile machining when cutting along the $<100>$ direction. An in-depth understanding of the anisotropic machinability of GaAs materials and of an effective approach for determining process parameters remains a significant knowledge gap for obtaining the ductile-regime diamond turning of GaAs.

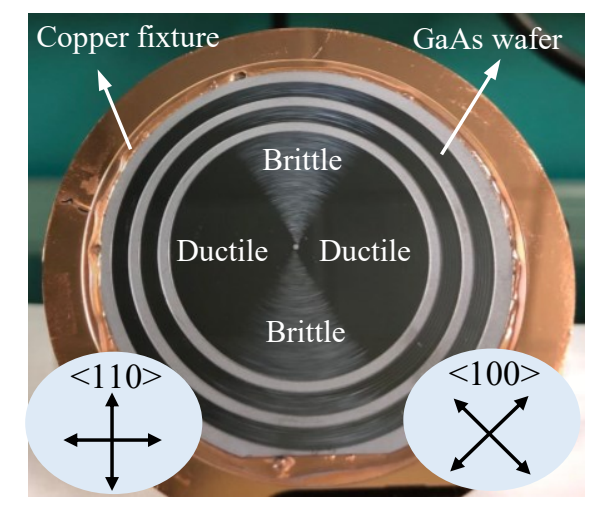

Fig. 1. Anisotropic machinability of (001)-oriented GaAs.

The aforementioned literature results were gained using diamond tools with a rake angle of $0^{\circ}$. An abundance of literature has demonstrated that brittle material undergoes phase transformation when a high hydrostatic press exists by adopting a negative tool rake angle like the indenter [27-31]. In this case, the brittle material around the tool's rake face would then become plastic enough to sustain plastic flow, which is plastic material removal [27]. Therefore, it is significant to discover the detailed machining characteristics as well as the feasibility of obtaining smooth surfaces for anisotropic GaAs by using a diamond tool with a negative rake angle.

On the other hand, a nano-smooth surface on a brittle material can only be obtained when subsequent tool passes remove the brittle fractures generated along the tool edge and no fractures propagate into the finished bottom surface. Furthermore, a brittle fracture will take place along the tool edge when the chip thickness is larger than the critical undeformed chip thickness [23]. Therefore, the critical undeformed chip thickness is an 
important factor in evaluating the machinability of brittle materials during diamond turning. Blake et al. first proposed an 'uncut shoulder' to calculate the critical undeformed chip thickness (critical depth in the paper) for SPDT; however, the calculated value through theoretical equations is not precise when considering the influence of the machining system's vibrations on chip thickness $[25,29]$. In addition, the critical undeformed chip thickness was significantly influenced by feed rate, which results in a non-deterministic and complicated procedure. Furthermore, many researchers have adopted tape cutting or plunge cutting on brittle materials to measure the cross-sectional profile of microgrooves and then evaluate the critical undeformed chip thickness (critical depth of cut in some papers), since it is easier and more precise than the 'uncut shoulder' method [20, $27,28,30,31,32]$. However, the speed of plunge cutting or tape cutting is much slower than that in SPDT. Yan et al. pointed out cutting speed may affect the thermal and dynamical aspects of a cutting process [30]; thus, the critical depth of cut gained at low speed may be drastically different from the value under a high-speed condition. Hence, a novel method for determining critical depth of cut under a high speed comparable to SPDT must be studied for the diamond cutting of brittle materials.

Aiming to bridge the aforementioned knowledge gaps, this study examined the fundamental machining characteristics and feasibility of ductile-regime SPDT of GaAs by using a diamond tool with a negative rake angle, and a novel approach for determining the critical depth of cut was proposed under the condition of a high cutting speed comparable to SPDT. To reveal the reason for strong anisotropy and brittleness, the mechanical properties, including hardness, elastic modulus and fracture toughness, were also studied along specific crystal orientations. Afterwards, the anisotropic machinability and critical depth of cut were analysed, aiming to realise the complete ductile machining of (001)-oriented GaAs. Finally, the material remove mechanism was studied by observing the crystal structure beneath the cut surface.

\section{Experimental details}

\subsection{Mechanical testing experiments}

The polished undoped single crystal gallium arsenide (GaAs) wafers (diameter of $25 \mathrm{~mm}$, thickness of $1 \mathrm{~mm}$, Wafer Technology Ltd. (UK)) were used in mechanical testing experiments. These wafers were grown at low pressure from high purity polycrystalline GaAs in a vertical temperature gradient (VGF-vertical gradient freeze). Vickers indentation experiments were carried out on an ultra-precision machine-micro-3D in order to determine hardness and fracture toughness, as shown in Fig. 2 (a). The (001)-oriented GaAs specimen was glued on an aluminum block, and ultrasonic cleaned with 95 vol. \% medical alcohol. Then, the specimen was fixed on a 
three-component piezoelectric dynamometer (Kistler 9129 AA) with a resolution of $1 \mathrm{mN}$, thus the load of indentation was measured in real time. As shown in Fig. 2 (a), a current-controlled linear slide rail was used to apply the load through NC program, which enables a minimum displacement of $0.2 \mu \mathrm{m}$ and a maximum load of up to $40 \mathrm{~N}$. A Vickers indenter HV-3 at loads of 0 50 kgf was connected to the end of the linear slide rail to produce impression on the sample.
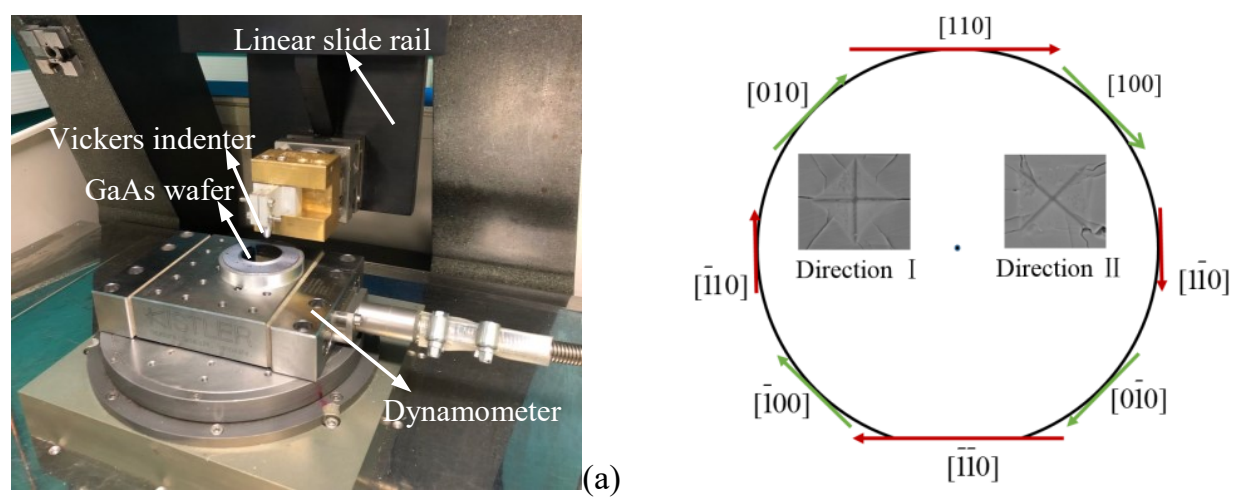

(b)

Fig. 2. (a) Experimental setup, (b) Crystal orientations on (001) plane and two directions for indentation tests.

The indentation experiments were conducted along direction I and direction II respectively, as shown in Fig. 2 (b). Diagonals of indenter in indentation acted in the similar way of tool edge with largely negative rake angle during diamond turning. Therefore, the indentation along direction $\mathrm{I}$ is similar to diamond cutting along the $<110>$ direction (including [110], [110], [110], [110]), while another direction is similar to diamond cutting along the $<100>$ direction (including [100], [010], [100], [010]). For each direction, in view of indentation size effect [33], twelve maximum loads $(0.25 \mathrm{~N}, 0.5 \mathrm{~N}, 0.75 \mathrm{~N}, 1.0 \mathrm{~N}, 2.0 \mathrm{~N}, 3.0 \mathrm{~N}, 4.0 \mathrm{~N}, 5.0 \mathrm{~N}, 8.0 \mathrm{~N}, 11.0 \mathrm{~N}, 14.0$ $\mathrm{N}, 17.0 \mathrm{~N}$ ) were used to make impression, and the tests were repeated seven times at each maximum load. All tests were performed with a 10 s holding time and 30 s loading-unloading period. The indentation impressions at different loads were firstly imaged by scanning electron microscope (SEM, TM-1000, Hitachi, Japan), and then all the two diagonals of the square shaped indentation impression and cracks generated at the corners of the impressions were measured by image analysis software (Digimizer, Belgium). The averages of diagonals and crack sizes at each maximum load were calculated by considering seven indents.

Experiments of testing elastic modulus were carried out on a Nano indentation system (Keysight G200), where the diamond indenter was a Berkovich tip with a tip radius of $100 \mathrm{~nm}$. The maximum loads were set as 10 $\mathrm{mN}, 100 \mathrm{mN}$ and $500 \mathrm{mN}$ respectively. The tests were repeated three times at each load with the loadingunloading period of $25 \mathrm{~s}$. Similar to the directions in Fig. 2 (b), one of the diagonals of indenter perpendicular to 
the $<110>$ direction was defined as direction I, while one of the diagonals of indenter parallel to $<110>$ was regard as direction II.

\subsection{Single point diamond turning experiments}

The SPDT face cutting of GaAs ((001) plane) were carried out on a custom-built machining system, where cross linear $X$ and $Z$ axes carry the tool holder, and the air bearing work spindle was fixed on a granite bed, as shown in Fig. 3 (a). The work spindle has a total indicator reading error of less than $1 \mu \mathrm{m}$ in the axial direction and a maximum speed of $10000 \mathrm{rpm}$. Each linear axis comprises of a dovetail section air bearing carriage with direct drive DC brushless linear motor and a high resolution encoder. Their positioning repeatability is less than $0.5 \mu \mathrm{m}$ and straightness error is smaller than $0.3 \mu \mathrm{m}$. The polished GaAs wafers with a size of $\Phi 50 \mathrm{~mm} \times 0.5 \mathrm{~mm}$ were glued on a copper fixture and then connected to the vacuum chuck of machining system. Single crystal diamond tool was fixed on the tool holder and cutting force was monitored by a three-component piezoelectric dynamometer (Kistler 9129 AA), as shown in Fig. 3 (a). All the experiments were conducted under dry cutting condition, since coolant cannot improve the machined surface quality according to our previous cutting results. In order to study the influence of rake angle on the machined surface quality, three types of diamond tools were used, and the cutting edge radius was measured by using an Atomic Force Microscope (AFM, DI Dimension 3100). The detailed machining parameters were listed in Table 1.
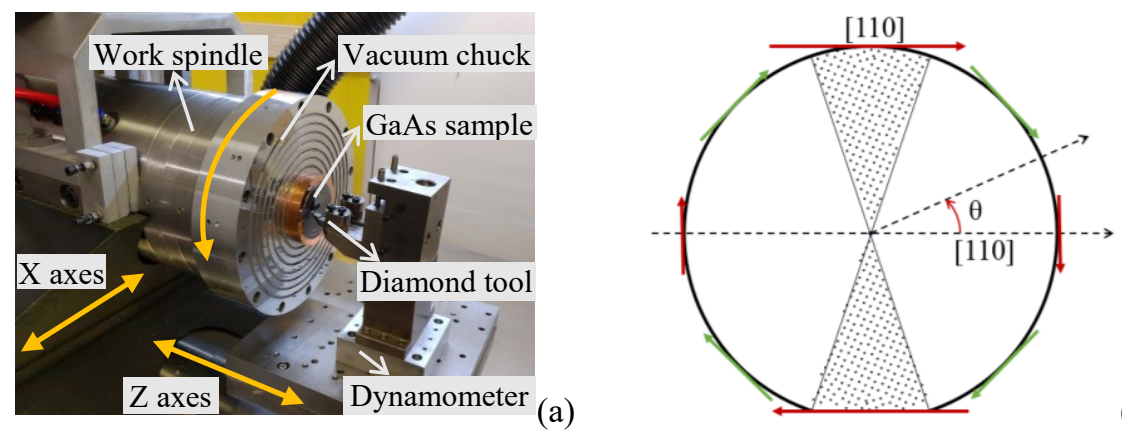

(b)

Fig. 3. (a) Experimental setup of SPDT, (b) Measurement for anisotropic surface quality.

The machined surface was firstly ultrasonic cleaned with 95 vol. \% medical alcohol, and then the distribution of surface roughness and topography in circumferential direction was measured using AFM with the method illustrated in Fig. 3 (b), in which the angle between radial direction of measuring position and that along [110] orientation was defined as $\theta$. Moreover, the angle $\theta$ ranges from $0^{\circ}$ to $360^{\circ}$ with an angle interval of $5^{\circ}$. The machined surface was also imaged by the SEM and a white light interferometer (Zygo NewView 5000). In 
order to observe the subsurface damage caused by cutting process, a slice cut off from a machined surface was measured by Transmission Electron Microscope (TEM, Themis Z, Thermo Fisher, USA).

Table 1 Machining parameters of SPDT.

\begin{tabular}{llll}
\hline SI. no. & Parameters & Unit & Values \\
\hline 1 & Tool nose radius of diamond tools & $\mathrm{mm}$ & 5 \\
2 & Rake angle & degree & -25 (tool I), -30 (tool II), -40 (tool III) \\
3 & Clearance angle & degree & 10 (tool I), 10 (tool II), 20 (tool III) \\
4 & Cutting edge radius of diamond tools & $\mathrm{nm}$ & 73.79 (tool I), 101.10 (tool II), 61.14 (tool III) \\
5 & Feed rate & $\mu \mathrm{m} / \mathrm{rev}$ & $0.5,1.0,1.5,2.0,2.5$ \\
6 & Cutting speed & $\mathrm{m} / \mathrm{s}$ & 1.84 \\
7 & Depth of cut & $\mu \mathrm{m}$ & 10 \\
\hline
\end{tabular}

\section{Mechanical properties along two directions}

Many researchers have found that crystallographic orientation had a significant effect on the brittle-ductile transition of single crystal brittle material, meanwhile brittle micro fracture first occurred for cutting along specific crystallographic direction $[21,27,29-32]$. But the mechanism of crystallographic orientation dependence was not yet understood. Diamond cutting process is regard as similar to indentation test especially for diamond tool with largely negative rake angle [27]. Moreover, material mechanical properties is known as playing an important role in determining the critical undeformed chip thickness which indicates the machinability of brittle materials [29]. Thus the hardness and fracture toughness of crystalline materials obtained from the indentation tests, should be different in different crystallographic orientation like the crystallographic orientation dependence appeared in the diamond cutting process. In order to reveal this issue, indentation tests for two directions (shown in Fig. 2 (b)) were designed on the (001) plane.
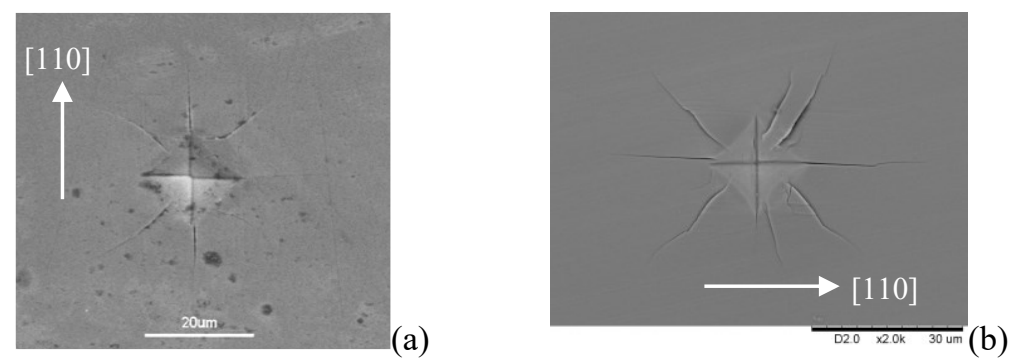

Fig. 4. (a) Indentation impression obtained under the load of $0.98 \mathrm{~N}$ [24], (b) Indentation impression along direction I obtained at the load of $1.0 \mathrm{~N}$ in this study.

As shown in Fig. 4 (a), Wang et al., carried out indentation tests at room temperature on undoped (001)oriented GaAs with the maximum load of $0.98 \mathrm{~N}$ [24], when diagonals of indenters were parallel to [110] and 
[110] orientations which is the same as the direction I in this study. From Fig. 4 (b), it can be seen that the size of indentation impression and the pattern of cracks are very similar to that achieved by Wang, et al. Therefore, the indentation test procedure and results are considered to be reasonable and reliable in this study.

\subsection{Vickers hardness and the indentation size effect}

The Vickers hardness is defined as the ratio of the applied load via a geometrical indenter of defined shape to the contact projected area, which can be described as $[33,34]$ :

$$
H_{v}=1.8544 \times 10^{3} \frac{P}{d^{2}}
$$

where $H_{v}$ is the Vickers hardness in GPa, $P$ is the applied load in Newtons and $d$ is the average value of the two diagonal lengths in $\mu \mathrm{m}$. When the applied loads varied from $0.25 \mathrm{~N}$ to $17 \mathrm{~N}$, the Vickers hardness values of GaAs were calculated and plotted in Fig. 5, where each plotted data points and its error bar are the averages of seven indent measurements and their standard deviations, respectively. For two directions, the hardness firstly increased and then decreased, and tended to be stable in the end with the increase of applied loads, which is similar to the results of single crystal $\mathrm{SiC}$ reported by Li et al. [35]. The Vickers hardness of $5.45 \mathrm{GPa}$ in direction I was determined to be slightly higher than the value of $5.27 \mathrm{GPa}$ in direction II. However, the relationship between hardness and load for single crystal GaAs differs from other typical brittle materials, for which the hardness decreases and then tends to be stable with the increase of loads [33]. This phenomenon may be attributed to its special zincblender structure [36].

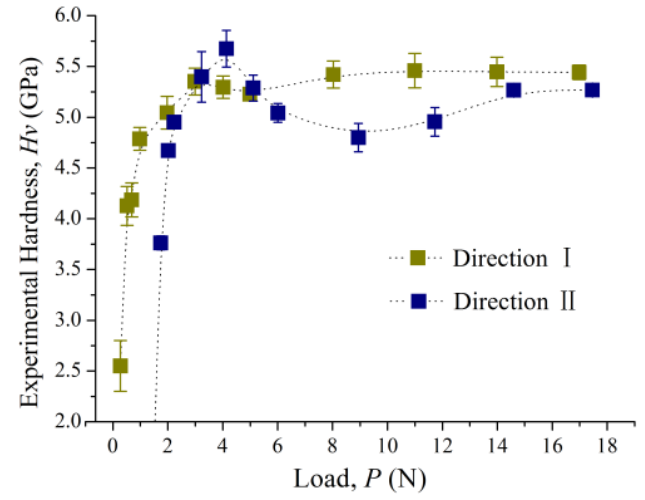

Fig. 5. Vickers hardness varied with applied load.

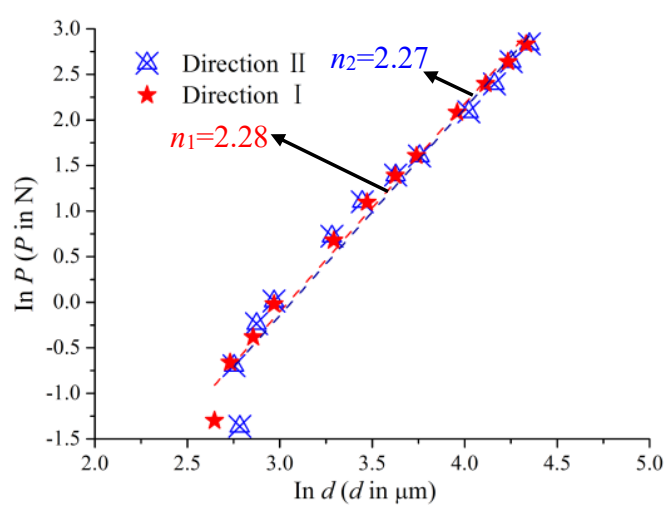

Fig. 6. $\ln P$ versus $\ln d$ fitting curves.

Moreover, the indentation size effect was also considered to exist in indentation test of GaAs, so the classical Meyer's law was analysed and plotted in Fig. 6. The Meyer's index $n$ is given by [33] 


$$
P=A d^{n}
$$

where $A$ is constant and $d$ is the average value of the two diagonal lengths in $\mu \mathrm{m}$. The indentation size effect was usually related to the deviation of the $n$-value from 2 [33]. As shown in Fig. 6, the $n$ values of two directions were larger, but not smaller than 2 like many ceramic materials [33]. Although $n$ value of direction I was close to the other direction, the indention impression showed very different from one to the other in Fig. 7. Obvious elastic recovery for the edge of impression were observed along the $<100>$ orientation for direction I. In addition, the external applied energy cannot be completely absorbed by elastic and plastic deformation, but formed cracks at middle point of each edge along the $<100>$ orientation, which is the intersection of the $\{110\}$ plane and the (001) plane, as shown in Fig. 7 (a). For GaAs material, $\{110\}$ plane is the preferential cleavage plane [36], so the cracks mainly propagated along the $<100>$ orientation for direction II shown in Fig. 7 (b), but no elastic recovery was found in the edge of impression. It can be explained that $<110>$ orientation in Fig. 7 (b) is the intersection of the $\{111\}$ planes and the (001) plane [24], where the $\{111\}$ slip planes is easier to produce dislocation and plastic deformation than elastic deformation [36].
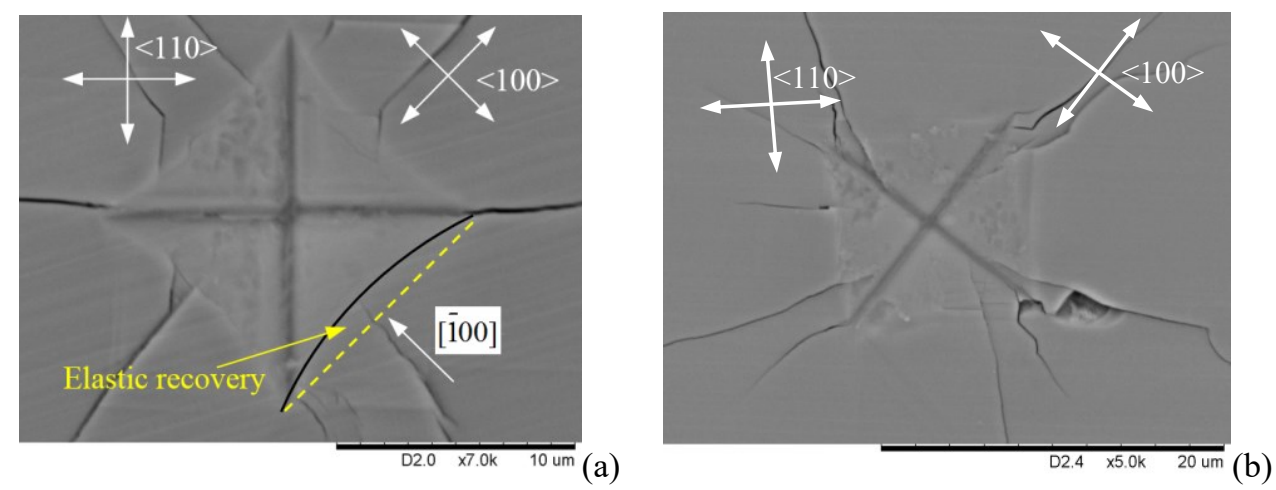

Fig. 7. The indentations obtained at the load of 0.5N. (a) Direction I, (b) Direction II.

\subsection{Elastic modulus}

Elastic modulus $E_{s}$ can be obtained by the following equation [37]:

$$
\frac{1}{E_{r}}=\frac{\left(1-v_{s}^{2}\right)}{E_{s}}+\frac{\left(1-v_{i}^{2}\right)}{E_{i}}
$$

where $E_{r}$ and $v_{s}$ are the reduced elastic modulus and Poisson's ratio of the specimen, respectively. $E_{i}$ and $v_{i}$ are elastic modulus and Poisson's ratio of the indenter. The indenter parameters used in this study are $E_{i}=1141$ GPa and $v_{i}=0.07$ and it was assumed that $v_{s}=0.31$ for the GaAs [38]. The reduced modulus can also be determined by analysing the load-displacement curve according to the following equation: 


$$
E_{r}=\frac{S}{2} \cdot \sqrt{\frac{\pi}{A_{c}}}
$$

where $A_{c}$ is the projected area of contact between the specimen and the indenter at maximum load, $S$ is the stiffness of the test material, and can be obtained from the initial unloading slope by evaluating the maximum load and maximum depth, which is $S=\mathrm{d} P / \mathrm{d} h$ [37].

The loading-unloading curves for the nanoindentation test at different loads are shown in Fig. 8. It is clear that the maximum depth $h_{\max }$ and the residual plastic depth after unloading $h_{r p}$ at different loads are almost the same for the two directions. In addition, both the load-displacement curves of two directions creep at the maximum load, which can be attributed to plastic deformation of GaAs material. The elastic recovery is relative to the plastic deformation during the indentation process, and it can be expressed by the ratio of elastic recovery $\Delta e$ from the loading-unloading curve, as follows [38]

$$
\Delta e=\frac{h_{\max }-h_{p p}}{h_{\max }} \times 100 \%
$$

No obvious difference for the ratio of elastic recovery was found between the two directions, and the average value was calculated as $42.14 \%$ taking into consideration of all three maximum loads, which is very close to the ratio of elastic recovery of $40 \%$ reported by Fang et al. at maximum load of $3 \mathrm{mN}$ on (100)-oriented GaAs surface [38].
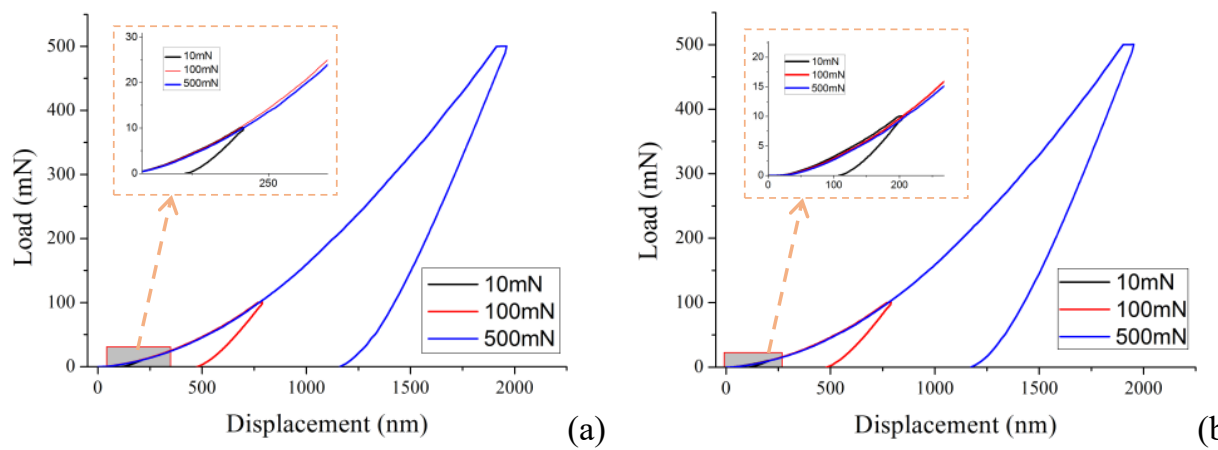

Fig. 8. The load-displacement curves. (a) Direction I, (b) Direction II.

Through considering all the nanoindentation tests, the elastic modulus values of GaAs were calculated and plotted in Fig. 9, where the error bars were their standard deviations. It can be seen that when the load was larger than $100 \mathrm{mN}$, the elastic modulus tended to be stable at a value of $109 \mathrm{GPa}$ and showed no difference between the two directions. The results implied the elastic modulus did not exhibit crystallographic orientation 
dependence when adopting the Berkovich indenter, since we found that one edge of indenter was along $<110>$ orientation while the other two edges were approximately along $<67250>$ or $<25670>$ orientation for each direction, as shown in Fig. 9. Hence, the elastic modulus of 109 GPa was used to calculate fracture toughness of two directions on (001) plane. Moreover, Fang et al. reported the elastic modulus of (100)-oriented GaAs ranged from $120 \mathrm{GPa}$ to $100 \mathrm{GPa}$ at different loads [38].

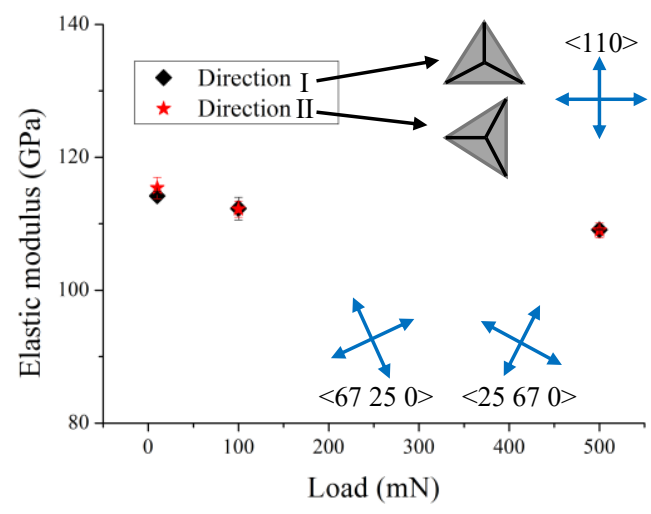

Fig. 9. The elastic modulus at different maximum load.

\subsection{Fracture toughness}

The typical cracks propagating at the corners of impression shown in Fig. 10 belong to radial-median cracks. Therefore, the fracture toughness can be evaluated by [33]:

$$
K_{c}=0.0154\left(\frac{E}{H_{v}}\right)^{1 / 2}\left(\frac{P}{c^{3 / 2}}\right)
$$

where $c$ is the crack lengths initiated at the centre of indentation impression and $E$ is elastic modulus. Wang et al. have ever found surrounding the indentation site was a square region of slip lines lying along the $<110>$ directions [24]. Similarly, a lot of slide lines along the [110] and [110] orientations appeared outside the impression and emerged from cracks for direction I in Fig. 10 (a). However, Fig. 10 (b) showed slide lines distributed within the impression area along all $<110>$ orientations (including [110], [110], [110], [110]) for direction II, since $<110>$ direction is the intersection of the $\{111\}$ slip planes with the (001) sample surface [24]. Because the formation of slide lines arising from dislocations within impression area consumed some energy, the length of crack propagating from the corner of the impression in the case of direction II should be shorter than that of direction I, which was proved by the data shown in Fig. 11 (a). 

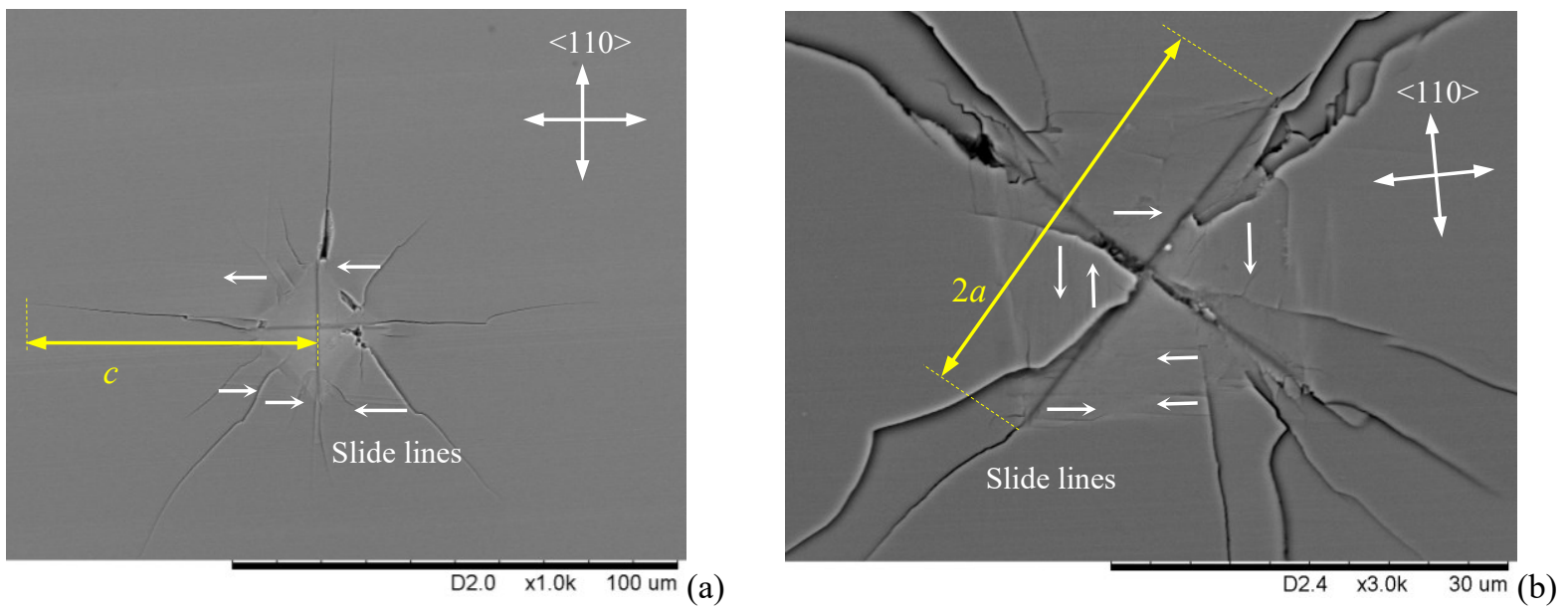

Fig. 10. Indentation impression and cracks at the load of 4 N. (a) Direction I, (b) Direction II.

During calculating fracture toughness, the ratio of crack length $c$ to diagonal half-length $a$ was generally required to satisfy the condition of $c / a \gg 2$ [39], so the fracture toughness was evaluated at the loads ranging from $2.0 \mathrm{~N}$ to $17.0 \mathrm{~N}$. The average value and error bar based on seven indentation tests for each load were plotted in Fig. 11 (b). It is clear that the fracture toughness of direction II is obviously higher than that of direction I at each load, which may be caused by the shorter crack length for direction II than direction I at the same load. The average values of fracture toughness considering all the loads were determined as 0.482 $\mathrm{MPa} \cdot \mathrm{m}^{1 / 2}$ and $0.579 \mathrm{MPa} \cdot \mathrm{m}^{1 / 2}$ for Direction I and Direction II, respectively. Hence, the results achieved in this study proves that both hardness and fracture toughness presents crystallographic orientation dependence.
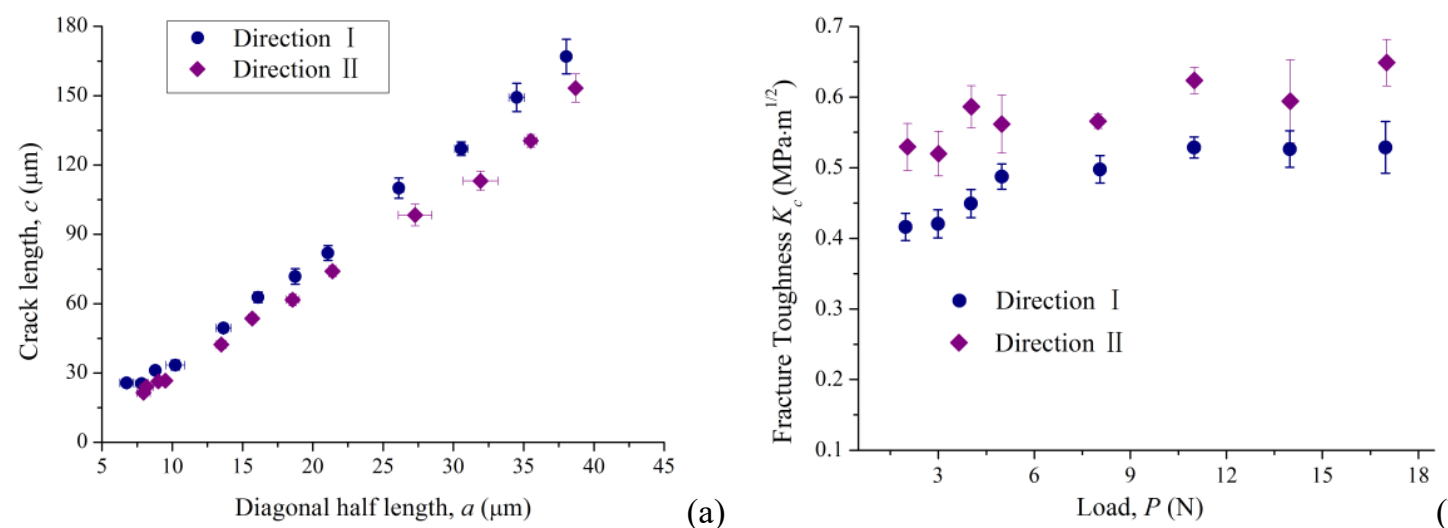

Fig. 11. Crack length and fracture toughness. (a) The relationship between crack length and diagonal half length, (b) Fracture toughness at different load.

\section{Analysis of anisotropic machined surface quality obtained by SPDT}


The machined surface quality on GaAs wafer exhibited strong anisotropy by using the parameters listed in Table 1. Through observing the machined surface roughness $\left(R_{a}\right)$ distribution in circumferential direction, it was found that the surface roughness was higher than $10 \mathrm{~nm}$ when the angle $\theta$ (illustrated in Fig. 3 (b)) varied in the ranges of $60^{\circ}-130^{\circ}$ and $245^{\circ}-315^{\circ}$. Furthermore, the maximum machined surface roughness $\left(R_{a}\right)$ appeared at the angle of $80^{\circ}$, not at $90^{\circ}$ ([110] orientation) as shown in Fig. 12. This phenomenon maybe attributed to the findings that some cracks propagated along the $\{110\}$ plane while others generated from a high density of dislocation along the $\{111\}$ plane $[36,40]$, and cutting at the angle of $80^{\circ}$ maybe the most beneficial direction for the crossing of cracks in different directions to form brittle fracture. However, although the surface roughness was lower than $10 \mathrm{~nm}$ when cutting along [110] orientation $\left(\theta=0^{\circ}\right)$ and [110] orientation $\left(\theta=180^{\circ}\right)$, a few of micro cracks caused by micro fracture were found on the machined surface.

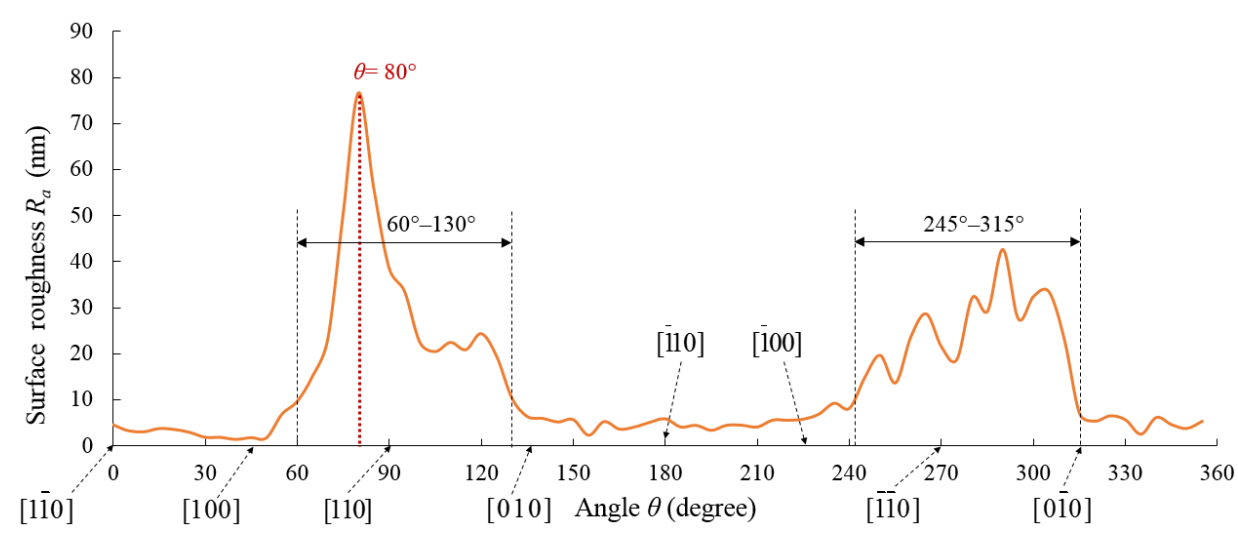

Fig. 12. Distribution of the machined surface roughness in the circumferential direction after SPDT by using tool II and feed rate of $2.5 \mu \mathrm{m} / \mathrm{rev}$.

Therefore, in this study, brittle fracture index $I$ was defined and classified into six levels to further evaluate anisotropic machined surface quality. The $I$ value of 0 means crack free; level 1 represents that the machined surface shows regular cutting trace and a few small cracks; level 2 is relative to the flat surface with obvious cutting trace, many cracks and a few micro pits; level 3 means the surface with high-density micro pits and no cutting trace; level 4 represents that uneven surface exhibits a few macro brittle pits besides micro pits; level 5 means most serious brittle fracture featured by a large amount of macro brittle pits. As shown in Fig. 13, brittle fracture index reached 5 only in the case of cutting at the angle of $80^{\circ}$. The ductile response with crack free on machined surface was observed to distribute within four angle ranges of $20^{\circ}-50^{\circ}, 135^{\circ}-175^{\circ}, 195^{\circ}-220^{\circ}$ and $315^{\circ}-350^{\circ}$, that is near the cutting along four $<100>$ orientations. On the other hand, the machined surface exhibits brittle fracture when cutting near the directions in four $<110>$ orientations. This result can be explained 
by the crystallographic orientation dependence of hardness and fracture toughness shown in Fig. 5 and Fig. 11 (b), in which diagonals of indenter along the $<110>$ orientations were relative to higher hardness and lower fracture toughness as compared to the diagonals along the $<100>$ orientations.

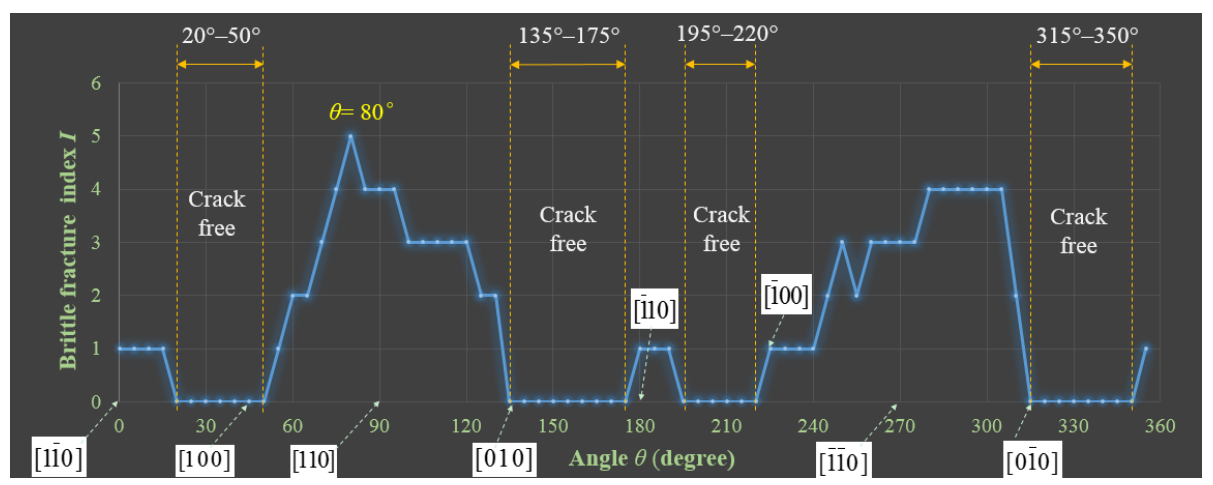

Fig. 13. Distribution of brittle fracture index in circumferential direction on (001) plane.

Nevertheless, the brittle fracture indexes $I$ of the machined surface along the [110] and [110] orientations are much larger than that along [110] and [110] orientations, which may be caused by the noncentrosymmetric structure of GaAs as a polar crystal [24]. Wasmer et al. reported that in the glide set configuration of GaAs, $\alpha$ dislocation was along the [110] orientation with type III (As) atoms, while $\beta$ dislocation was along the [110] orientation with type $\mathrm{V}(\mathrm{Ga})$ atoms [40]. In addition, the maximum velocity of $\beta$ dislocation is $2.5 \mu \mathrm{m} / \mathrm{s}$, but the maximum velocity of $\alpha$ dislocation reaches $250 \mu \mathrm{m} / \mathrm{s}$ [40]. The cracks propagating on the $\{111\}$ plane are associated with a high density of dislocations. So, the brittle fracture on the machined surface showed very different from cutting along [110] and [110] orientations to cutting along other two $<110>$ orientations.

As mentioned before, only a few micro cracks caused by brittle fractures were found on the machined surface at the angle of $\theta=0^{\circ}$ (cutting along [110] orientation). So this angle was chosen to analyse the influence of feed rate and tool' rake angle on surface defect. According to surface topography measured by the AFM, five larger pits were determined, and then the depths of pits were calculated through obtaining their cross-sectional profiles. The average depth of five pits, named as depth of pitting damage, was expressed in Fig. 14 (a). Among the three diamond tools, tool III with rake angle of $-40^{\circ}$ was found better to suppress the generation of surface defect in comparison to tools with rake angle of $-25^{\circ}$ and $-30^{\circ}$, since crack-free machined surfaces were obtained by using this tool under the feed rate smaller than $2.5 \mu \mathrm{m} / \mathrm{rev}$. It can be explained that larger negative rake angle can cause deeper phase transformation or dislocation layer through higher hydrostatic pressure, 
which was supported by the results of normal cutting force. As shown in Fig. 14 (b), the diamond tool with the larger rake angle generated the smaller normal cutting force, since the deeper phase transformation or dislocation layer (softer than perfect single crystal GaAs) was produced and then removed in the form of chips during cutting by using the tool with larger rake angle. Accordingly, tool I with rake angle of $-25^{\circ}$ was regard as the worst to achieve ductile machining of GaAs. Fig. 14 (a) also shows the depth of surface pitting defects increases with the increase of feed rate, which arises from the increase of the chip thickness.
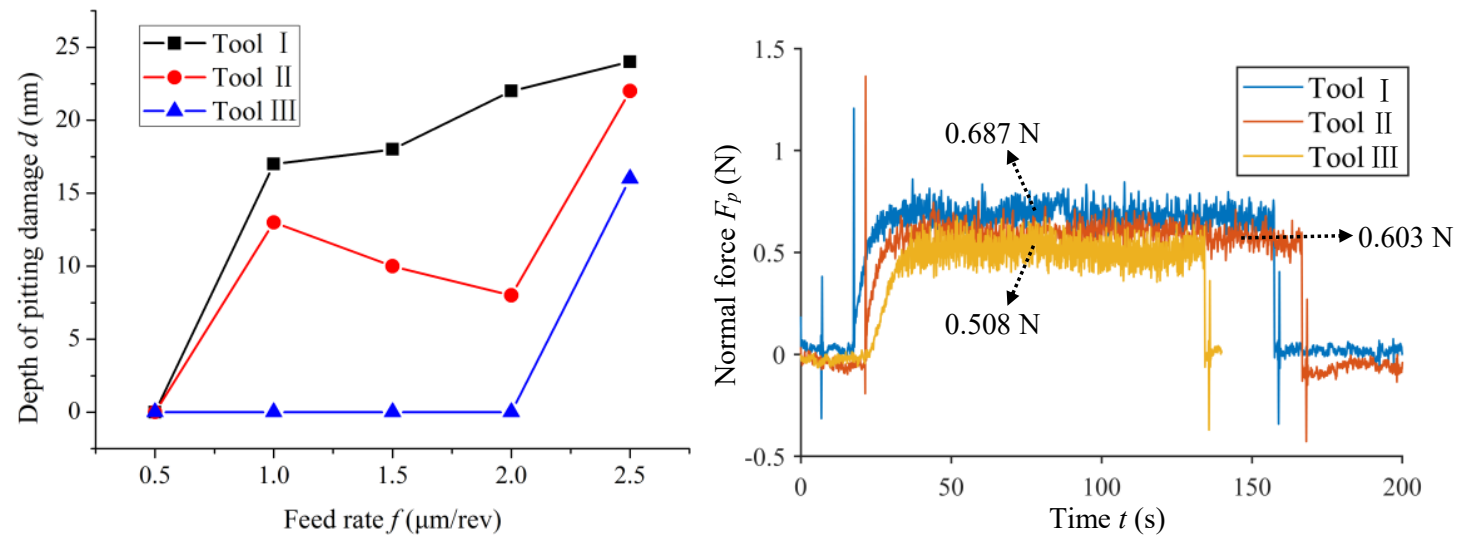

Fig. 14. Cutting performance of diamond tools with different rake angle. (a) Depth of surface pitting damage obtained under different feed rates, (b) Normal cutting forces at the feed rate of $1.0 \mu \mathrm{m} / \mathrm{rev}$.

\section{Critical depth of cut in the hardest cutting direction}

\subsection{An approach of evaluating critical depth of cut}

According to the distribution of machined surface roughness and brittle fracture index in Figs. 12 and 13, the direction with the angle of $\theta=80^{\circ}$ was regard as the hardest cutting direction, which is close to the [110] orientation. In other words, once this direction can achieve ductile cutting, it will be feasible to realise smooth surface on the (001) plane of GaAs. Therefore, in this paper the critical depth of cut was only studied in the hardest cutting direction. As most of the researches gained critical depth of cut through plunge cutting or tape cutting under low speed which cannot be regard as the true value in real SPDT, in this study a novel method was proposed to evaluate the critical depth of cut under a high cutting speed comparable to SPDT. Fig. 15 shows the detailed experimental setup, in which a slice of GaAs was cut out from the wafer along radial direction with the angle of $\theta=80^{\circ}$. Then the slice was glued on an aluminum fixture with one side slightly higher than the other side. In Fig. 15, the GaAs wafer was not connected to the fixture, and just used to illustrate the slice of GaAs. During SPDT with a spindle speed of $500 \mathrm{rpm}$ and a feed rate of $600 \mathrm{~mm} / \mathrm{min}$, the nominal depth of cut was set 
as $1 \mu \mathrm{m}$ in every cutting circulation, and the cutting stopped until a row of inclined grooves appeared on the slice of GaAs, as shown in Fig. 15.

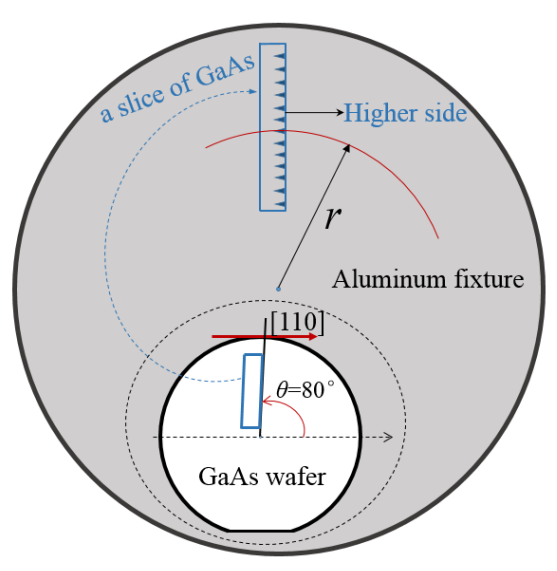

Fig. 15. Schematic diagram of experimental setup.

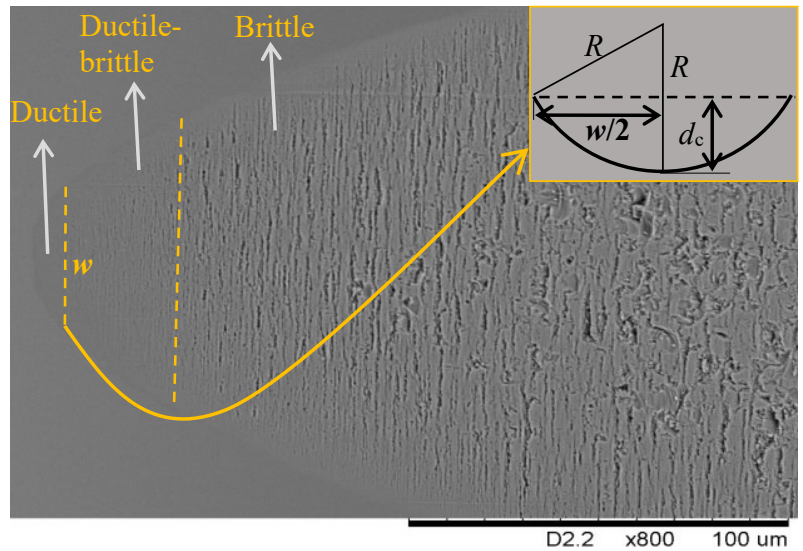

Fig. 16. Surface topography of inclined groove.

\subsection{Critical depth of cut under the high speed}

Cutting speed of every inclined groove was calculated by its radial distance $r$ and spindle speed. The machined surfaces of the inclined groove were measured by SEM to determine the position of brittle-ductile transition, and then the width of groove $w$ was measured by image analysis software, as shown in Fig. 16. Accordingly, the critical depth of cut $d_{c}$ can be calculated by

$$
d_{c}=R-\frac{1}{2} \sqrt{4 R^{2}-w^{2}}
$$

where $R$ is tool nose radius. In this case, vibration of machining system did not have remarkable influence on calculation of the critical depth of cut. From Fig. 16, it can be seen that the surface radial cracks approximately propagated in the direction perpendicular to the cutting speed within the region of brittle-ductile transition, which is near the [110] and [110] orientations.

As the diamond tool with the rake angle of $-25^{\circ}$ achieved the worst machined surface finish, only the other two diamond tools with larger negative rake angles were used to evaluate the critical depth of cut. The relationship between the cutting speed and the critical depth of cut was plotted in Fig. 17. Corresponding to the results shown in Fig. 14, the tool III with rake angle of $-40^{\circ}$ has better performance of suppressing brittle fracture, and is able to generate deeper critical depth of cut in comparison to the tool II. On the other hand, cutting speed does not have obvious influence on the critical depth of cut, so the average value of $d_{c}$ was calculated through considering all the cutting speeds. The average $d_{c}$ of $26.57 \mathrm{~nm}$ was achieved using diamond 
tool III, which is almost 2.6 times of tool II. The extremely low critical depth of cut implies it is very challenging to realise ductile cutting of GaAs.

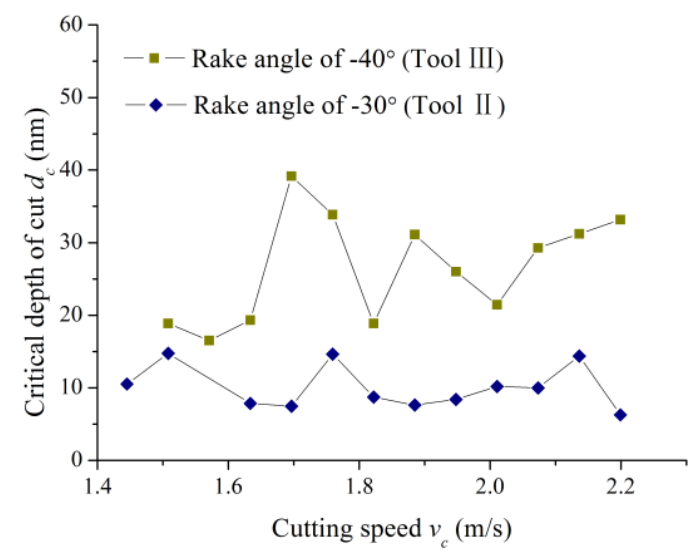

Fig. 17. The critical depth of cut at different cutting speed.

\section{Generation of nano-smooth surface}

It is well recognized in SPDT of brittle materials that the nano-smooth surfaces can only be obtained when subsequent tool passes remove the brittle fractures generated along the tool edge, and no fractures propagate into the machined surface. Therefore, the length and growing direction of initiated crack at the position of the critical undeformed chip thickness (or critical depth of cut) was extremely significant to achieve nano-smooth surface. Lawn et al. has ever proposed a model for crack initiation in elastic/plastic indentation fields. They determined critical conditions for the growth of penny-like "median cracks" from sub-surface flaws beneath sharp indenter [41]. Accordingly, the threshold load $P^{*}(\mathrm{~N})$ and threshold crack length $C^{*}(\mu \mathrm{m})$ of generating initial median cracks were given by [41]

$$
\begin{gathered}
C^{*}=\left(\frac{1.767}{\theta^{2}}\right)\left(\frac{K_{c}}{H}\right)^{2} \\
P^{*}=\left(\frac{54.47 \alpha}{\eta^{2} \theta^{4}}\right)\left(\frac{K_{c}}{H}\right)^{3} K_{c}
\end{gathered}
$$

where $K_{c}$ and $H$ are the fracture toughness (MPa $\mathrm{m}^{1 / 2}$ ) and hardness (GPa), $\alpha=2 / \pi$ for Vickers diamond indenter, $\theta \approx 0.2$ and $\eta \approx 1$. As mentioned before, the diamond tool with largely negative rake angle in cutting acted like Vickers indenter in indentation, thus the indentation tests were conducted along direction I and direction II which are close to the hardest cutting direction (cutting along $<110>$ orientations) and the easiest cutting direction (cutting along $<100>$ orientations), respectively. On the basis of equations (8) and (9), the threshold 
load and threshold crack length were calculated and listed in Table. 2. It is obvious that the threshold load of generating cracks for the easiest direction was approximately 2.3 times of the hardest direction. Because the cutting force is directly related to the chip thickness in SPDT, the results also support that the critical depth of cut (or undeformed chip thickness) is extremely small along the hardest direction when compared to other typical brittle materials, for instance, higher than $300 \mathrm{~nm}$ for single crystal silicon and germanium by adopting largely negative rake angle [29].

Table 2 Parameters when cutting along the hardest (near $<110>$ orientation) and the easiest (near $<100>$ orientation) directions.

\begin{tabular}{cccccc}
\hline Parameters & $\begin{array}{c}\text { Hardness } \\
H_{v}(\mathrm{GPa})\end{array}$ & $\begin{array}{c}\text { Fracture toughness } \\
K_{c}\left(\mathrm{MPa} \cdot \mathrm{m}^{1 / 2}\right)\end{array}$ & $\begin{array}{c}\text { Threshold } \\
\text { load } P^{*}(\mathrm{mN})\end{array}$ & $\begin{array}{c}\text { Threshold crack } \\
\text { length } C^{*}(\mu \mathrm{m})\end{array}$ & $\begin{array}{c}\text { Critical depth of } \\
\text { cut } d_{c}(\mathrm{~nm})\end{array}$ \\
\hline $\begin{array}{c}\text { Cutting along } \\
\text { hardest direction }\end{array}$ & 5.45 & 0.482 & 7.23 & 0.345 & $\frac{26.57 \text { for tool III }}{10.06 \text { for tool II }}$ \\
$\begin{array}{c}\text { Cutting along } \\
\text { easiest direction }\end{array}$ & 5.27 & 0.579 & 16.64 & 0.533 & - \\
\hline
\end{tabular}

The generation of cutting chip and machined surface in SPDT was illustrated in Fig. 18. Supposing that the critical crack length is $C^{*}(\mu \mathrm{m})$, the critical chip thickness is $d_{\mathrm{c}}(\mu \mathrm{m})$ and the allowed maximum feed rate for generating smooth surface is defined as $f_{\max }(\mu \mathrm{m} / \mathrm{rev})$. From Fig. 18, if $f=f_{\max }$, the height of point $E$ equals $C^{*}+G_{0}$, where $G_{0}$ is the vertical distance from point $\mathrm{C}$ to point B given by $f^{2} / 8 R$. Through analysing geometrical relationship between diamond tool and GaAs wafer shown in Fig. 18, the allowed maximum feed rate $f_{\max }$ can be deduced as

$$
f_{\max }=\sqrt{R^{2}-\left(R-d_{c}\right)^{2} \cos ^{2} \theta}-\left(R-d_{c}\right) \sin \theta
$$

where $\theta=\cos ^{-1}\left(\left(R-C^{*}-G_{0}\right) / R\right)$. Additionally, the maximum thickness of chip $d_{\max }$ should meet the requirement of $d_{\max } \leq d_{\mathrm{c}}$ for generating crack-free surface, and $d_{\max }$ under certain process parameters was well known to be calculated by:

$$
d_{\mathrm{max}}=R-\sqrt{R^{2}+f^{2}-2 f \sqrt{2 R a_{p}-a_{p}^{2}}}
$$

in which $a_{\mathrm{p}}$ was nominal depth of cut in SPDT, and its maximum value can be calculated by $d_{\max } \leq d_{\mathrm{c}}$ in the case of $f=f_{\max }$. Here, the critical undeformed chip thickness $d_{\mathrm{c}}$ is regarded as the same with the critical depth of cut $d_{\mathrm{c}}$ described in Section 5. The maximum feed rate and maximum nominal depth of cut to generate nano-smooth surface were calculated and listed in Table 3. 


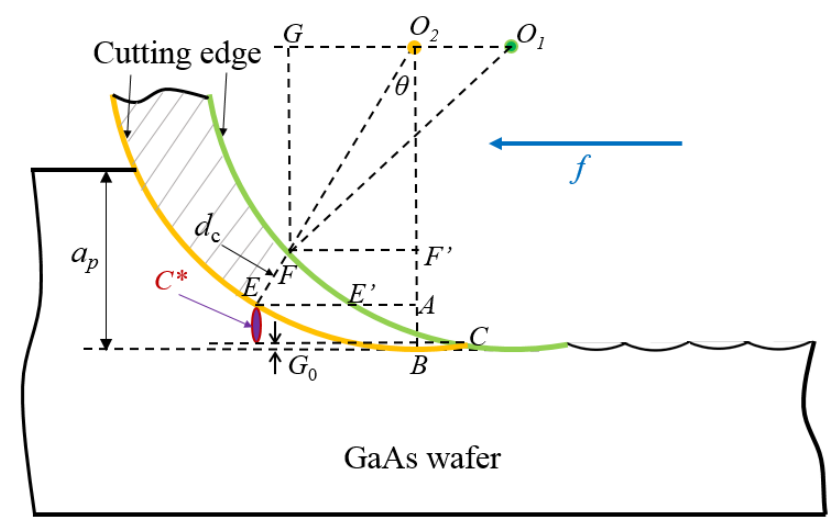

Fig. 18. The schematic diagram of cutting process in SPDT.

Table 3 Machining parameters for generating crack-free surface.

\begin{tabular}{ccccc}
\hline Parameters & $\begin{array}{c}\text { Threshold crack } \\
\text { length } C^{*}(\mu \mathrm{m})\end{array}$ & $\begin{array}{c}\text { Critical depth } \\
\text { of cut } d_{c}(\mathrm{~nm})\end{array}$ & $\begin{array}{c}\text { Maximum feed rate } \\
f_{\max }(\mu \mathrm{m} / \mathrm{rev})\end{array}$ & $\begin{array}{c}\text { Maximum depth of } \\
\text { cut } a_{\mathrm{pmax}}(\mu \mathrm{m})\end{array}$ \\
\hline $\begin{array}{c}\text { Diamond tool II with } \\
\text { rake angle of }-30^{\circ}\end{array}$ & 0.345 & 10.06 & 0.850 & 0.356 \\
\hline $\begin{array}{c}\text { Diamond tool III with } \\
\text { rake angle of }-40^{\circ}\end{array}$ & 0.345 & 26.57 & 2.218 & 0.372 \\
\hline
\end{tabular}

It is worth noting that the values listed in Table $\mathbf{3}$ were calculated under ideal conditions without considering any material defects within GaAs wafer and the vibration occurred in the machining process. Hence, the real $f_{\max }$ and $a_{\mathrm{pmax}}$ during SPDT should be smaller than the values calculated. In view of the limitation of motion precision of the machining system, the nominal depth of cut was set as $0.3 \mu \mathrm{m}$, and the feed rate decreased from $2.0 \mu \mathrm{m}$ to $0.5 \mu \mathrm{m}$ with a space of $0.3 \mu \mathrm{m}$. Diamond cutting tests were carried out under the spindle speed of $800 \mathrm{rpm}$ on the (001) plane of a GaAs wafer using tools II and III. Unfortunately, nano-smooth surface cannot be achieved along the hardest direction with all the feasible feed rates for the diamond tool II, and the reason needs to be further studied. But for diamond tool III, when the feed rate was decreased to $0.5 \mu \mathrm{m} / \mathrm{rev}$, crack-free machined surface was successfully generated along all the orientations, as shown in Fig. 19. Due to the vibration of machining system, irregular cutting traces can be clearly observed on the machined surface but without any brittle fracture feature, and thus machined surface toughness $R_{a}$ only reached $3 \mathrm{~nm}$ in the hardest cutting direction. The experimental results proves that the method of calculating maximum feed rate and depth of cut is very effective to guide the ductile machining of brittle materials. In addition, it also supports that the method of determining the critical depth of cut under high speed and maximum feed rate is very viable to realise ductile-regime diamond turning of GaAs. 


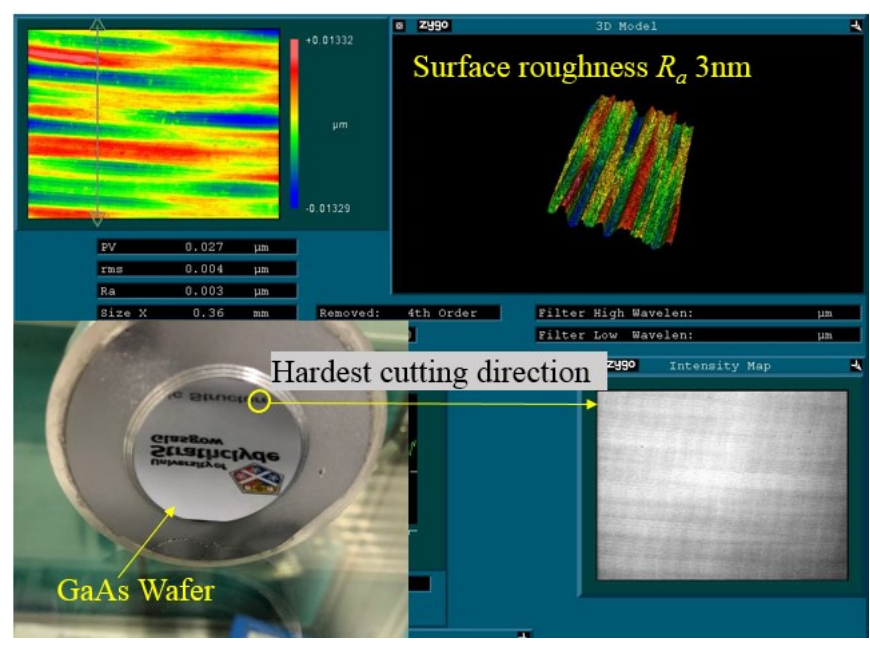

Fig. 19. Ductile-regime turning of GaAs wafer and surface quality machined along the hardest cutting direction.

In order to further observe the subsurface damage caused by diamond cutting, a cross-sectional sample was cut off from the position marked by yellow circle in Fig. 19, and then the cross section, which is perpendicular to cutting speed direction in SPDT, was measured by TEM. As shown in Fig. 20 (a), the three layers can be clearly observed beneath the cut surface, and named as the heavily deformed layer, the dislocation pileup layer and the dislocation extension layer. More significantly, No crack was found within the subsurface layer. It can be seen that the heavily deformed layer just beneath cut surface also keeps single crystal structure, as proved in Fig. 20 (b) and (f), and it did not transformed into amorphous or nano-crystal structure under the machining pressure. However, the deformed layer with average thickness of $43 \mathrm{~nm}$ contains a large amount of dislocations, meanwhile, lattice deformation can be observed along the cutting direction due to high shear stress and high pressure. As the depth of subsurface layer increases, both the shear stress and pressure decrease, thus the crystal defect is dominated by high-density dislocations and formed dislocation pileup layer with the thickness of 99nm, as shown in Fig. 20 (e). Finally, the density of dislocations gradually decreases with the depth increases in the dislocation extension layer, which has an average thickness of $97 \mathrm{~nm}$. Additionally, almost all the dislocation extended along (111) plane and a few of line dislocations extended to the deeper region, as supported by Fig. 20 (a) and (d). Fig. 20 (g-j) exhibits no impurity atom was penetrated into subsurface layer during cutting process.

Consequently, the material removal mechanism during ductile machining of single crystal GaAs can be described as: high contact pressure and shear stress caused crystal defect consisting of lattice deformation and high-density dislocations, so the material surrounding diamond tool nose was soften because of crystal defect and then removed more easily through plastic deformation caused by the initiation and extension of dislocation. 
The subsurface damage layer remains single crystal structure, meanwhile, no crack or impurity atom was found beneath the cut surface.

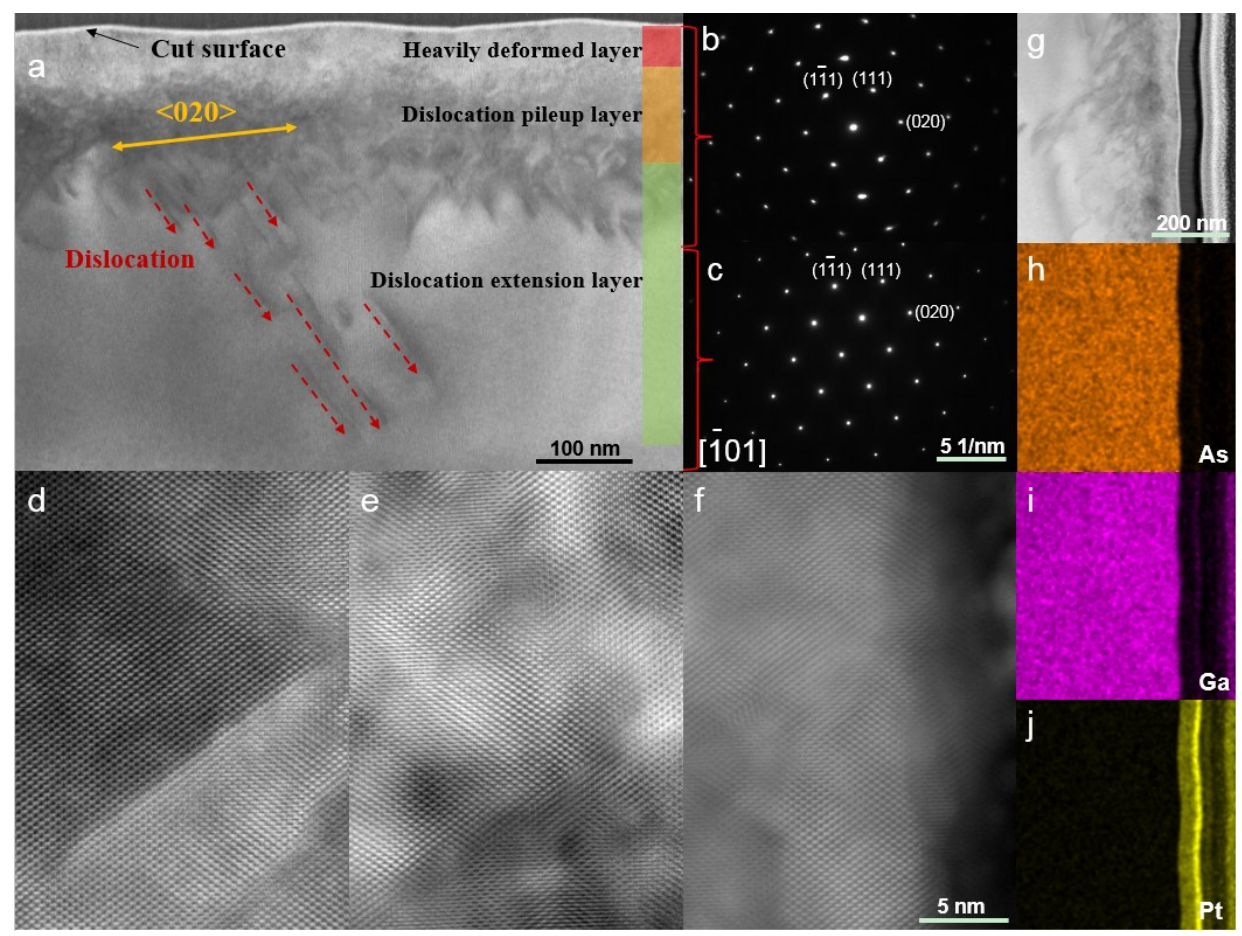

Fig. 20. (a) The BF-STEM image of cross-sectional sample, showing a clear three-layer structure, that is, the heavily deformed layer, the dislocation pileup layer and the dislocation extension layer. (b) and (c) The selected electron diffraction patterns (SAEDs) corresponding to areas marked with red braces. (d), (e) and (f) The HAADF-STEM images corresponding to dislocation extension layer, dislocation pileup layer and heavily deformed layer, respectively. (g), (h), (i) and (j) The BF-STEM image, EDS mapping of As, Ga and Pt, respectively.

\section{Conclusions}

In order to reveal anisotropic machinability of single crystal GaAs, crystallographic orientation dependence of hardness, elastic modulus and fracture toughness was studied by means of indentation tests in two different directions. Through analyzing anisotropic surface quality after SPDT and the influence of tool's rake angle, the critical depth of cut in the hardest cutting direction was determined under high cutting speeds comparative to SPDT. The feasibility of generating nano-smooth surface and material removal mechanism were also investigated in this study. The main conclusions can be drawn as follows:

(1) The (001)-oriented GaAs material was tested to be harder and more brittle when indented along direction I in comparison to direction II, which may be attributed to the results of the elastic recovery along the $<100>$ 
orientations and slide lines along the $<110>$ orientations within impression area of direction II as the intersections of slip plane $\{111\}$ and (001) plane. Additionally, the Vickers hardness of single crystal GaAs firstly increases and then decreases, and tends to be stable in the end with the increase of applied loads, due to its special zincblender structure. Thus, the results implies cutting along the $<110>$ orientations should be much easier to produce brittle fracture than that along the $<100>$ orientations.

(2) The machined surface roughness and brittle fracture index on GaAs wafer after SPDT exhibits strong anisotropy, which can be explained by the crystallographic orientation dependence of hardness and fracture toughness. Furthermore, the ductile response with crack free is quite difficult to achieve when cutting along near the four $\left\langle 110>\right.$ orientations, and the hardest cutting direction appears at the angle of $\theta=80^{\circ}$, but not $\theta=90^{\circ}$ along the [110] orientation. In addition, the brittle fracture indexes at the angles along the [110] and [110] orientations are much larger than that along the [110] and [110] orientations, which may be caused by the noncentrosymmetric structure of GaAs as a polar crystal.

(3) Diamond tool with larger negative rake angle was proved to have the better cutting performance for ductile machining of GaAs. On the basis of the method proposed in this study, the critical depth of cut of $26.57 \mathrm{~nm}$ was obtained using diamond tool with rake angle of $-40^{\circ}$, which is almost 2.6 times that of tool with rake angle of $-30^{\circ}$. Moreover, within the region of brittle-ductile transition on the inclined groove surface, radial cracks approximately propagated in the direction perpendicular to cutting speed, which was near the [110] and [110] orientations.

(4) The proposed new evaluation approach is very effective to determine critical depth of cut and the allowed maximum feed rate to realise ductile-regime diamond turning. In this study, crack-free machined surface was successfully generated along all the orientations on the (001)-oriented GaAs using the diamond tool with rake angle of $-40^{\circ}$, in which the material remove mechanism is considered as plastic deformation caused by high-density dislocations. In addition, no crack or impurity atom was found beneath the cut surface and the subsurface layer remains single crystal structure. The results prove that the approach is viable to guide the ductile regime diamond turning of brittle materials.

\section{Acknowledgements}


The authors gratefully acknowledge the financial support from the EPSRC (EP/K018345/1), the National Key R\&D Program of China (2018YFA0703400), the National Natural Science Foundation of China (51775482) and the Hebei Province Natural Science Foundation of China (E2016203372) for this work.

\section{Data Statement}

All data underpinning this publication are openly available from the University of Strathclyde Knowledge Base.

\section{References}

[1] Yoon J, Jo S, Chun IS, et al. GaAs photovoltaics and optoelectronics using releasable multilayer epitaxial assemblies. Nature 2010; 465: 329-333.

[2] Sun L, Wang L, Liu J, et al. Anomalous enhancement of the absorption coefficient of GaAs in a p-n junction. Superlattice. Microst. 2018; 122: 80-84.

[3] Shan T, Qi X. Design and optimization of GaAs photovoltaic converter for laser power beaming Infrared. Phys Techn. 2015; 71: 144-150.

[4] Wu J, Shao D, Dorogan VG, et al. Intersublevel Infrared Photodetector with Strain-Free GaAs Quantum Dot Pairs Grown by High-Temperature Droplet Epitaxy, Nano Lett. 2010; 10: 1512-1516.

[5] Adokanou K, Inal K, Montmitonnet P, et al. Investigation on the effect of external mechanical stress on the DC characteristics of GaAs microwave devices. Microelectron. Reliab. 2015; 55: 1697-1702.

[6] Wu X, Peltola T, Arsenovich T, et al. Processing and characterization of epitaxial GaAs radiation detectors. Nucl. Instrum Meth. A 2015; 796: 51-55.

[7] Sagatova A, Zatko B, Necas V, et al. From single GaAs detector to sensor for radiation imaging camera. Appl. Surf. Sci. 2018; 461: 3-9.

[8] Sagatova A, Zatko B, Dubecky F, et al. Radiation hardness of GaAs sensors against gamma-rays, neutronsand electrons. Appl. Surf. Sci. 2017; 395: 66-71.

[9] Zhao J, Qin C, Guo J, et al. Iterative correction of the thickness for transmission-mode GaAs photocathode optical performance. Optik. 2018; 175: 334-339.

[10] Gangopadhyay A, Maros A, Faleev N, et al. Strain relaxation in low-mismatched GaAs/GaAs1-xSbx/GaAs heterostructures. Acta. Mater. 2019; 162: 103-115. 
[11] Ma Y, Ballesteros G, Zajac JM, et al. Highly directional emission from a quantum emitter embedded in a hemispherical cavity. Opt. Lett. 2015; 40 (10): 2373-2376.

[12] Othman MK, Dolah A, Omar NA, et al. Design of experiment (DOE) for thickness reduction of GaAs wafer using lapping process. ICSE2006 Proc. 2006, Kuala Lumpur, Malaysia.

[13] Yu B, Gao J, Chen L, et al. Effect of sliding velocity on tribochemical removal of gallium arsenide surface. Wear. 2015; 330-331: 59-63.

[14] Wu YH, Chang L. Chemical polishing method of GaAs specimens for transmission electron microscopy. Micron. 2010; 41: 20-25.

[15] Venkatesh VC, Inasaki I, Toenshof HK, et al. Observations on polishing and ultraprecision machining of semiconductor substrate materials. CIRP Ann. 1995; 44 (2): 611-618.

[16] Matovu JB, Ong P, Leunissen LHA, et al. Fundamental investigation of chemical mechanical polishing of GaAs in silica dispersions: material removal and arsenic trihydride formation pathways. ECS J. Solid State Sci. Technol. 2013; 2 (11): 432-439.

[17] Zhou H, Lai LJ, Du YJ, et al. Fabrication of microstructures on GaAs with pulsed electrochemicalwet stamping. Electrochimi. Acta. 2013; 111: 680-684.

[18] Pawlak R, Tomczyk M, Walczak M, et al. Selected problems in IR and UV laser micromachining of Si and GaAs in submillimeter scale. Microelectron. Eng. 2016; 151: 47-52.

[19] Malshe A, Deshpande D. Nano and microscale surface and sub-surface modifications induced in optical materials by femtosecond laser machining. J. Mater. Process. Tech. 2004; 149: 585-590.

[20] Wang J, Zhang X, Fang F, et al. Diamond cutting of micro-structure array on brittle material assisted by multi-ion implantation. Int. J. Mach. Tool Manufact. 2019; 137: 58-66.

[21] Mukaida M, Yan J. Ductile machining of single-crystal silicon for microlens arrays by ultraprecision diamond turning using a slow tool servo. Int. J. Mach. Tool Manufact. 2017; 115: 2-14.

[22] Goel S. Luo X, Comley P, et al. Brittle-ductile transition during diamond turning of single crystal silicon carbide. Int. J. Mach. Tool Manufact. 2013; 65: 15-21. 
[23] Sun Z, To S, Zhang S. A novel ductile machining model of single-crystal silicon for freeform surfaces with large azimuthal height variation by ultra-precision fly cutting. Int. J. Mach. Tool Manufact. 2018; 135: 111.

[24] Wang S, Pirouz P. Mechanical properties of undoped GaAs. III: Indentation experiments. Acta. Mater. 2007; 55: 5526-5537.

[25] Jasinevicius RG. Influence of cutting conditions scaling in the machining of semiconductors crystals with single point diamond tool. J. Mater. Process. Tech. 2006; 179: 111-116.

[26] Fang FZ, Yuan ZJ, Ultra-precision cutting for gallium arsenide. In Proc. ASPE Annual Meeting, pp. 62-66. 1999.

[27] Yan J, Asami T, Harada H, et al. Fundamental investigation of subsurface damage in single crystalline silicon caused by diamond machining. Precis. Eng. 2009; 33 (4): 378-386.

[28] Fang FZ, Zhang GX. An experimental study of edge radius effect on cutting single crystal silicon. Int. J. Adv. Manuf. Technol. 2003; 22: 703-707.

[29] Blake PN, Scattergood RO. Ductile-regime machining of germanium and silicon. J. Am. Cerom. SOC. 73 1990; 141: 949-57.

[30] Yan J, Asami T, Harada H, et al. Crystallographic effect on subsurface damage formation in silicon microcutting. CIRP. Ann. Manuf. Techn. 2012; 61: 131-134.

[31] Lai M, Zhang X, Fang F, et al. Effects of crystallographic orientation and negative rake angle on the brittle ductile transition and subsurface deformation in machining of monocrystalline germanium. Precis. Eng. 2019; 56: 164-171.

[32] Wang S, An C, Zhang F, et al. An experimental and theoretical investigation on the brittle ductile transition and cutting force anisotropy in cutting KDP crystal. Int. J. Mach. Tool Manufact. 2016; 106: 98-108.

[33] Chicot D, Tricoteaux A. Mechanical properties of ceramics by indentation: principle and applications, ceramic material, InTech, 2010; ISBN978-953-307-145-9.

[34] Roy TK. Assessing hardness and fracture toughness in sintered zinc oxide ceramics through indentation technique. Mat. Sci. Eng. A-Struct. 2015; 640: 267-274. 
[35] Wasmer K. Parlinska-Wojtan M, Graça S, et al. Sequence of deformation and cracking behaviours of GalliumeArsenide during nano-scratching. Mater. Chem. Phys. 2013; 138: 38-48.

[36] Li C, Zhang F, Meng B, et al. Simulation and experiment on surface morphology and mechanical properties response in nano-indentation of 6H-SiC. J. Mater. Eng. Perform. 2017; 26 (3): 1000-1009.

[37] Oliver WC, Pharr GM. An improved technique for determining hardness and elastic modulus using load and displacement sensing indentation experiments. J. Mater. Res. 1992; 7 (6): 1564-1580.

[38] Fang TH, Chang WJ, Lin CM. Nanoindentation and nanoscratch characteristics of Si and GaAs. Microelectron. Eng. 2005; 77: 389-398.

[39] Zia AW, Zhou Z, Shum PW, et al. The effect of two-step heat treatment on hardness, fracture toughness, and wear of different biased diamond-like carbon coatings. Surf. Coat. Tech. 2017; 320: 118-125.

[40] Wasmer K, Parlinska-Wojtan M, Gassilloud R, et al. Plastic deformation modes of gallium arsenide in nanoindentation and nanoscratching. Appl. Phys. Lett. 2007; 90: 031902.

[41] Lawn BR, Evans AG. A model for crack initiation in elastic/plastic indentation fields. J. Mater. Sci. 1977; 12: $2195-2199$. 